\title{
THE IMPACT OF TOTAL QUALITY MANAGEMENT ON ORGANIZATIONAL PERFORMANCE IN SMES
}

\author{
Cosmina Laura RAT ${ }^{a}$, Cristina TOADERE ${ }^{b}$, Alina Rodica $G A L^{c}$ \\ a, b, c, Babes-Bolyai University, Cluj Napoca, Romania
}

DOI: $10.24818 / \mathrm{IMC} / 2020 / 03.19$

\begin{abstract}
SMEs are subject to strong competition on the market, which makes them increasingly concerned about the quality of products and services, activities and processes, in a holistic approach. Increasing competition on the market causes SMEs to give increasing importance to quality, respectively TQM in order to ensure competitive advantage in an increasingly dynamic and uncertain environment. The study aims to analyze the concerns of SMEs, for the implementation of TQM taking into account specific issues and problems, in order to identify good practices according to the requirements of international standards ISO 9001:2015. At the same time, the study aims to empirically test and explain the effect of variables, which define TQM, in SMEs, on their performance measured using non-financial indicators, such as: organizational effectiveness, employee satisfaction and customer satisfaction. The results obtained will facilitate the emphasis on key success factors, which have a significant effect on the effectiveness of the QMS quality management system, and their proper monitoring, in order to improve the quality of the entire organization. We also aim to study the extent to which TQM facilitates achieving the strategic objectives of the enterprise, in the field of quality, in order to ensure its competitive advantage.
\end{abstract}

KEYWORDS: Total Quality Management; SMEs; organizational performance;customer satisfaction; employee satisfaction.

\section{INTRODUCTION}

SMEs are subject to strong competition on the market, which makes them increasingly concerned about the quality of products and services, activities and processes, in a holistic approach. Increasing competition on the market causes SMEs to give increasing importance to quality, respectively TQM in order to ensure competitive advantage in an increasingly dynamic and uncertain environment.

TQM defines the strategic dimension of the enterprise, in the field of quality, and ensures the application of concepts, methods, tools and principles of quality management in all spheres of activity of the enterprise, which includes external stakeholders, namely customers, suppliers, community, etc., which ensures the competitive advantage of the market by continuously improving quality and increasing productivity (Bell \& Omachonu, 2011; Ilies \& Crisan, 2011; Juran, 1999; Olaru et al., 2011).

The study aims to analyze the concerns of SMEs, for the implementation of TQM taking into account specific issues and problems, in order to identify good practices according to the requirements of international standards ISO 9001: 2015.

At the same time, the study aims to empirically test and explain the effect of variables, which define TQM, in SMEs, on their performance, measured using non-financial indicators, such as:

\footnotetext{
* Corresponding author. E-mail address: cosmina.rat@econ.ubbcluj.ro
} 
organizational effectiveness, employee satisfaction and customer satisfaction. The results obtained will facilitate the emphasis on key success factors, which have a significant effect on the effectiveness of the QMS quality management system, and their proper monitoring, in order to improve the quality of the entire organization. We also aim to study the extent to which TQM facilitates achieving the strategic objectives of the enterprise, in the field of quality, in order to ensure its competitive advantage.

\section{STUDY OF LITERATURE}

TQM integrates all processes, which directly or indirectly contribute to quality improvement in an organization, through a holistic approach to quality, based on methods, techniques and tools for continuous improvement. From the moment of acceptance of the idea of quality improvement by all employees, it becomes a strategic objective of the organization, which is why Juran (1999) uses the concept of "strategic quality management" defined in terms of quality trilogy, respectively its functions based on three interdependent processes, as it follows:

- quality planning;

- keeping quality under control;

- quality improvement. (Juran, 1999).

Grant et al., (2002) expresses his vision on TQM, which he sees as a different concept from the traditional business vision based on profit maximization. The author emphasizes the human dimension of this concept based on the following arguments:

- an employee becomes responsible for his own performance and the development of technological innovation by involving himself in the statistical control of the process. He must participate in an exchange of information and knowledge with other participants in the processes in the organization, in order to identify the causes that produce non-quality, which is why adequate training and instruction must be provided;

- it ensures the increase of the decision-making power of the employees, respectively the delegation of a part of the decision-making and control power to the lower levels, of the management, in order to overcome the cross-functional barriers, with important implications on the organizational structure and power balance, which positively influences the flow of communications and information in the organization (Grant et al., 2002).

According to J. Kelada (1990), the philosophy of TQM includes the following elements:

- the recognition of the primary role of the client;

- the employee is at the center of all the processes through which the total quality is achieved;

- all external partners, upstream, of the company (suppliers of resources, materials, financial, labor) and downstream (distributors, carriers, retailers, etc.) actively participate in achieving total quality (Olaru, 2004).

It can be defined as a strategy to improve the performance of a business, by involving all employees in order to meet all predetermined customer requirements, at the lowest possible cost, by improving the quality of processes, products / services, and skills of all employees involved. (Ellington et al., 1996; Fotopoulos \& Psomas, 2010; Psomas et al., 2013). The authors

approach the process in terms of the strategic dimension, emphasizing the need for long-term guidance of the process of continuous quality improvement.

TQM defines the strategic dimension of the enterprise, in the field of quality, which ensures the application of TQM concepts, methods, tools and principles in all spheres of activity of the enterprise, which includes external stakeholders, namely customers, suppliers, community, etc. which can ensure the competitive advantage on the market by continuously improving quality and increasing productivity. (Bell \& Omachonu, 2011; Chiarini, 2017; Evangelos \& Jiju, 2015; 
Fonseca, 2015a; Fotopoulos \& Psomas, 2010; Ilies, 2003; Ilies \& Crisan, 2011; Juran, 1999; Olaru et al., 2011).

It refers to the way in which an enterprise establishes and implements systems to ensure that quality is continuously improved in order to meet specifications. (Bell \& Omachonu, 2011). It is a business strategy that facilitates the achievement of these objectives, among which quality improvement occupies an important place, thus proving that it is a key factor in keeping costs within acceptable limits and increasing productivity, an essential condition for ensuring the strategic advantage of business. (Powell, 1995).

TQM is implemented by SMEs as part of their strategy for continuous quality improvement. Although there is evidence of a positive relationship between its effectiveness and the performance of organizations in the business environment, there are still many problems that if not resolved correctly lead to failure. (Brah et al., 2002; Brown, 2008; Demirbag et al., 2006; Garengo, 2009; Heras et al., 2002).

The implementation of total quality management in SMEs ensures, to a large extent, their competitiveness, in a business environment characterized by the elimination of barriers and ensuring the free flow of products and information, knowing that companies maintain their competitive advantage by reducing costs, improving quality products and innovation of new products.

One aspect pursued in the study is the answer to the question: How important is TQM, to improve the performance of SMEs in the field of industrial production in Romania.

In this context, SMEs must respond to the requirements and challenges of continuous quality improvement, as an important condition for ensuring competitive advantage, which is why they must respond promptly and effectively to complex and difficult processes of restructuring the processes and activities of these organizations. (Ilies \& Crisan, 2011; Juran, 1999; Olaru, 2004; Powell, 1995; Psomas et al., 2013).

The empirical study can be useful for SMEs, which seek to effectively implement and operate the TQM principles, to meet the requirements of ISO 9001; 2015, in order to improve customer satisfaction, with important effects in ensuring competitiveness. The study aimed to evaluate and analyze the impact of quality management on organizational performance in SMEs, which were the subject of research.

\section{METHODS}

The study aims to analyze the implementation of TQM principles in SMEs, more specifically, in the field of industrial production, regarding the identification and use of good practices in the field, in order to improve customer satisfaction and expectations, as well as to provide adequate support to the decision-making system in the process of developing and monitoring standards and measures for continuous quality improvement.

As a general objective of the study, the authors aimed to develop a model for evaluating and analyzing the influence of quality management effectiveness on organizational performance, measured using non-financial indicators (organizational effectiveness, customer satisfaction and employee satisfaction), based on the requirements of the ISO international standard. 9001: 2015. At the same time, it will seek to ensure a scientific managerial foundation, adequate to this study, in order to identify and implement good management practices, which will ensure the increase of organizational performance by promoting a competitive and sustainable business model in SMEs.

The specific objectives of the study refer to the evaluation and analysis of the implementation of TQM principles and practices regarding the implementation and operationalization of QMS in the SMEs that were the object of the study.

At the same time, the influence of TQM effectiveness on organizational performance was analyzed, in order to improve the competitiveness of enterprises and raise the awareness of managers and 
other employees for a strategic approach to quality management, beyond its operational functions, to ensure adequate decision support in the improvement process of the products and services quality, an important condition in ensuring customer satisfaction and loyalty.

The study is exploratory and explanatory, based on a questionnaire-based survey, which allowed a more detailed analysis of the influence of the effectiveness of TQM practices on organizational performance measured using non-financial indicators, which allowed us to make a better liaison with the strategies, policies and procedures that SMEs apply.

A representative sample of 59 SMEs that implemented the new international standard ISO 9001: 2015 was chosen for the study. The respondents were the general managers and managers / managers responsible with quality management who are directly involved in the implementation, operationalization of QMS. After collecting and verifying the questionnaires, 52 valid questionnaires resulted, with a response rate of $88.13 \%$. The opinion poll is based on the questionnaire that measures respondents' perception of the effectiveness of quality management practices and the factors that determine organizational performance.

The items in the questionnaire were measured on a Likert scale with values from 1 to 5 (1 - total disagreement, - 5 - total agreement).

The statistical data obtained were uploaded to a database to be processed with the STATA software. For the analysis of the statistical population, respectively of the research sample, the indicators of descriptive statistics were used.

The results obtained from the processing of the questionnaires were subjected to the simple linear regression analysis, which allowed to obtain adequate information for the formulation of conclusions and recommendations.

Respondents' perceptions resulting from questionnaires and direct observation were used as a source of information.

The main constructed variables based on the items in the questionnaire are:

- Effectiveness of total quality management (Eff.QM);

- Organizational effectiveness (Eff.org);

- Employee satisfaction (Emp.satisf);

- Customer Satisfaction (Cust.satisf).

The hypotheses formulated in the study are the following:

- Hypothesis H1: The effectiveness of total quality management (Eff.QM) has a significant and positive impact on organizational performance;

- Hypothesis H1.1: The effectiveness of total quality management (Eff.QM) has a significant and positive impact on organizational effectiveness (Eff.org);

- Hypothesis H1.2: The effectiveness of total quality management (Eff.QM) has a significant and positive impact on employee satisfaction (Emp.satisf);

- Hypothesis H1.3: The effectiveness of total quality management (Eff.QM) has a significant and positive impact on customer satisfaction (Cust.satisf).

\section{RESULTS}

\subsection{Analysis of the variable Effectiveness of TQM}

For the analysis of the practices that determine the effectiveness of TQM, represented by the aggregate variable Eff.QM, the reliability analysis was performed, and as a result, a relevant structure of 25 primary items / variables was obtained, whose internal coherence is very good, (Cronbach's Alpha coefficient is 0.911).

As shown in Table 1, the average value of the variable Eff.QM is 3.8829, at an average deviation of 0.3345 and a standard error of 0.0384 , a quantity that shows a good approximation of the average of the variable to the real value of it, relative to the total statistical population. Thus, the real average 
will most likely be between $3,814(3,882-0,068)$ and 3,950 (3,882+ 0.068). The coefficient of variation (cv) is low $(0.0861)$, which means that the statistical population, which was the basis for calculating this variable, has a good degree of homogeneity.

Table 1. tabstat Eff_QM, statistics (mean count sd semean cv)

\begin{tabular}{ccccc} 
variable | mean & N & sd & se(mean) & cv \\
\hline Eff_QM | 3.882935 & 52 & 334564 & 0348807 & 0861627
\end{tabular}

Following the analysis of the variable Eff.QM, respectively of the primary variables that compose it, we can highlight the positive aspects regarding the effectiveness of the quality management practices in the SMEs, which are part of the sample. These refer to:

- performing analyses and evaluating the conformity of products and services (4.0753);

- the process approach facilitates the improvement of organizational performance, measured by quality improvement, (4.0108);

- monitoring and analysis of the operational performance of the enterprise in the field of quality, (4.0430);

- the objectives in the field of quality improvement are in accordance with the quality policy, (4.0538);

- the objectives in the field of quality improvement are relevant for the conformity of products and services to customer requirements, in order to ensure / improve customer satisfaction, $(4,0008)$;

- the objectives in the field of quality improvement are reviewed and updated if necessary, $(3,9462)$;

- identifying and capitalizing on opportunities for continuous quality improvement to promote customer orientation throughout the organization, as a basic principle of quality management and organizational culture (3.9355);

- the management of the enterprise performs analyses and evaluates the quality plan, respectively setting the objectives for quality, $(3,9247)$;

- the quality manual is available for customers and other stakeholders (3.9273);

- the management of the enterprise effectively and efficiently manages the quality improvement process (3.9140);

- the management of the enterprise determines the objectives in the field of quality improvement for the relevant functions, levels and necessary processes, in order to ensure the effectiveness and efficiency of QMS, (3,8925);

- enterprise management identifies and capitalizes on opportunities for continuous quality improvement to increase the effectiveness and efficiency of QMS, (3.8710);

- the company has systematic processes that it uses in pursuit of a higher quality and increase operational performance, (3.8280);

- identifying and capitalizing on opportunities for continuous quality improvement to ensure competitiveness, $(3,8431)$;

- the process approach ensures the definition and systematic management of the processes and their interactions so as to obtain the desired performance, in accordance with the strategy and quality policy, (3.8825);

- the process approach, as a principle of TQM facilitates the understanding of the requirements of the quality management system and their fulfillment; (3.9147);

- periodic monitoring and analysis of the level of quality and operational performance compared to those of competitors, (3.9785). 
The aspects, respectively the primary items / variables that register lower scores, and that can create difficulties in solving quality problems, refer to:

- providing adequately and effectively documented information on quality improvement objectives $(3,6559)$;

- successful capitalization on opportunities for continuous quality improvement by identifying and implementing good practices in the field (3.8495);

- identifying and capitalizing on opportunities for continuous quality improvement to ensure competitiveness, $(3,8431)$;

- integration of all functions and processes in the organization in order to improve quality, (3.7742);

- the objectives in the field of quality improvement are monitored and communicated in an adequate and effective way, (3,7957);

- there is an adequate system for evaluating the effectiveness of QMS, (3.7419);

- successful use of opportunities for continuous quality improvement, through the use of new technologies with superior performance (3.6957);

- the management of the enterprise performs analyses and evaluates the actions taken to evaluate and capitalize on opportunities and reduce risks in the field of quality improvement, $(3,7527)$.

The fact that, in our study, we focused on management and leadership practices, in the construct of the variable Eff.QM, had as aim to highlight the efforts of managers to ensure a strong customer orientation, and to identify and implement good management practices, in order to improve the effectiveness of continuous improvement processes, which play a key role in improving quality in SMEs.

\subsection{Organizational performance indicators}

In order to be successful in improving organizational quality and performance, SMEs need to implement an effective QMS that ensures a systematic approach to issues, along with the identification and implementation of good practices with high potential for effectiveness and efficiency considering the strategic function of quality management to ensure market competitiveness. We cannot conceive the achievement of organizational performance without a strategy and planning for quality improvement. In this context, training programs, measuring employee and customer satisfaction, supported by QMS, play a key role. Employee satisfaction, as an indicator of non-financial performance, expresses the potential, attitude and behavior of employees of the company in relation to the workplace and organization.

In our study, the improvement of organisational performance in SMEs, an important part of which is quality improvement, is founded on the efficiency of QMS practices, based on the ISO 9001:2015 international standard and organisational performance indicators, which is why this research is mainly applicative. To that purpose, we have sought to identify, validate and implement best practices in the field of management in order to ensure the effectiveness of QMS implementation and operationalisation and the improvement of organisational performance. According to ISO 9001:2015, a performance indicator must represent a characteristic measurement of the effectiveness and efficiency of plans for continuous quality improvement and of the steps taken to that purpose, one that has a significant impact on the performance objectives of SMEs.

Given the aim of the present study, we have set out to employ the following non-financial indicators for the measurement of performance from an inside perspective, as part of a construct which comprises the following:

- Organisational Effectiveness, represented by the variable 'Org.eff';

- Customer Satisfaction, represented by the variable 'Cust.satisf';

- Employee Satisfaction, represented by the variable 'Emp.satisf'. 


\subsubsection{Organisational Effectiveness}

The Organisational Effectiveness indicator, represented by the variable 'Org.eff', measures the effectiveness of management and leadership practices in relation to the attainment of the improvement aims of the SMEs being studied, of which quality improvement aims are an important part.

The 'Org.eff' variable as a indicator of the measure of organisational performance, comprises 21 items, while its structure is characterised by very good internal coherence (a Cronbach's Alpha coefficient of 0.957); it illustrates the essence of the management and leadership practices which ensure the improvement of the quality of all intercorrelated processes with the purpose of improving QMS implementation and operationalisation.

According to the data in table 2, the variable mean is 3.9644, for a mean deviation of 0.3341 and a standard error of 0.0358 ; this value indicates a good proximity between the mean of the variable and its true value in relation to the total population. Thus, the real mean will most likely stand somewhere between 3.893 and 4.035. The coefficient of variation (cv) of 0.0842 stresses the fact that the distribution of this variable is normal.

Table 2. tabstat Org_eff, statistics (mean count sd semean cv)

\begin{tabular}{|c|c|c|c|c|c|}
\hline variable | & mean & $\mathrm{N}$ & sd & se(mean) & $\mathrm{CV}$ \\
\hline Org_eff & 64483 & 52 & 341346 & .035823 & .084282 \\
\hline
\end{tabular}

\subsubsection{Customer Satisfaction}

The aim of using the Customer Satisfaction 'Cust.satisf' indicator from an inside perspective is to highlight the steps initiated by SMEs with respect to the satisfaction of their external customers and to the extent to which customers' needs are known. In order to analyse the manner of ensuring customer satisfaction as a fundamental objective of TQM, the 'Cust.satisf' variable was developed, which, following the reliability analysis, has been shown to have a relevant structure consisting of 14 items, which exhibits good internal coherence (the Cronbach's Alpha is 0.786).

As for the characteristics of the 'Cust.satisf' variable, (table 3), its mean is 3.9569, for a mean deviation of 0.3018 and a standard error of 0.0314 ; this value indicates a good proximity between the mean of the variable and its true value in relation to the total population. Thus, the real mean will most likely stand somewhere between 3.894 (3.956-0.062) and 4.018 (3.956+0.062). The coefficient of variation (0.0762) stresses the fact that the distribution if this variable is normal.

Table 3. tabstat Cust_satisf, statistics (mean count sd semean cv)

\begin{tabular}{ccccc} 
variable | mean & N & sd & se(mean) & cv \\
\hline Cust_satisf | 3.956957 & 52 & .3018214 & .0314671 & .0762761
\end{tabular}

The analysis of the 'Cust.satisf' variable highlights its positive aspects, according to the perception of questionnaire respondents, which refers to:

- proving the leadership's commitment to customer orientation by making sure that:

$\checkmark$ the improvement of customer satisfaction is an essential factor which is monitored consistently (4.1075);

$\checkmark$ quality improvement objectives are relevant to the conformity of products and services to customer demands in order to ensure/improve customer satisfaction (4.0008); 
- the improvement of organisational performance, as a result of TQM principles, translating into an increase in customer satisfaction (3.9785);

- the efficient use of quality improvement opportunities and the initiation of actions to improve customer satisfaction according to TQM principles (3.9348);

- the company possessing methods to obtain, monitor and review the information on customer satisfaction and customer meetings/contact (3.9725);

- the management focusing on getting to know customers' current and future needs and expectations as part of its relationship with customers (4.0645); a commitment to providing quality according to customers' demands and expectations (4.0538); a good knowledge of key success factors which ensure competitive advantage (3.9892); analysing and comparing customers' levels of satisfaction (3.9565).

The aspects which, in the respondents' opinion, deserve less appreciation and should be given more attention by the company management in order to improve market competitiveness are related to: monitoring satisfaction growth, not only for external customers, but also for the other interested parties (3.6387); obtaining customer feedback on delivered products and services (3.8360).

In order to foster the best customer relations possible, SMEs need to be permanently aware of customers' demands and, alongside their products, provide the best combination of associated services, which would enable them to develop and implement adequate and effective strategies and policies for managing customer relations. The evolution of information technology facilitates the manner in which companies implement these strategies, which involves collecting information in real time and enables enterprises to approach customers in a personalised way, as opposed to dealing with them in terms of customer segments, thus cultivating effective and long-lasting relations with customers, as a way for companies to restructure their strategy to gain a substantial competitive advantage.

\subsubsection{Employee Satisfaction}

Employee Satisfaction is a non-financial indicator that measures employee performance, which is an essential component of organisational performance from an inside perspective, given that it indicates the effectiveness of management strategies, policies, and practices within the group of SMEs which make the object of this study.

The analysis of employee satisfaction investigates the manner in which employees perceive the organisation and their attitude towards its aims, of which quality improvement is an important one.

The satisfaction of employees at their workplace has a positive impact on organisational commitment, which exerts a positive influence on employees' performance and their intention to remain within the organisation. The more committed employees are to the organisation, the less likely they are to leave (Camp, 1994; Mathieu \& Zajac, 1990).

In order to analyse employee satisfaction, we have constructed an aggregate variable, 'Emp.satisf', the structure of which consists of 10 primary variables; this variable has a high degree of internal coherence, due to the Cronbach's Alpha coefficient of 0.878 .

As can be seen in table 4, the 'Emp.satisf' variable registers a mean of 3.9608, for a mean deviation of 0.3686 and a standard error of 0.0384 ; this value indicates a good proximity between the mean of the variable and its true value in relation to the total population. Thus, the real mean will most likely stand somewhere between 3.9532 (3.9608-0.076) and 4.0360 (3.884+0.076). The coefficient of variation (cv) is low (0.9490), which means that the statistical population based on which this variable was calculated has a good level of homogeneity. 
Table 4. tabstat Emp_satisf, statistics (mean count sd semean cv)

\begin{tabular}{|c|c|c|c|c|c|}
\hline variable | & mean & $\mathrm{N}$ & sd & se(mean) & $\mathrm{CV}$ \\
\hline Emp_satisf | & 960854 & 52 & 686639 & .0384359 & 949022 \\
\hline
\end{tabular}

The analysis of statistical indicators for the primary variables which make up the 'Emp_satisf' variable highlights a series of significant positive aspects which led to the improvement of this performance indicator. They are the following:

- $\quad$ rewarding and acknowledging the merits of employees (3,9247);

- providing constant, constructive and honest management feedback on individual performance and results (3.9293);

- involving all employees in drafting the policy and aims regarding the improvement of business processes, of which quality improvement is an important part (3.9032);

- encouraging employee involvement and development by facilitating the open communication of employees' suggestions and opinions (4.0421);

- effective management and development of employees and their potential (4.0645);

- competent, consistent and fair managers (3.9311);

- ensuring an organisational climate based on trust in order to stimulate employee involvement at the workplace and their commitment to the organisation (3.9471);

- providing a pleasant work environment, which is supportive of employees' individual needs and family responsibilities (3.9005);

- encouraging employees to openly express their opinions at work meetings and communicate their concerns, results, and appreciation via formal paths (3.9983);

- employee participation in making workplace-related decisions, particularly with respect to scheduling and the way in which work tasks are carried out (3.9677).

The indicator regarding employee satisfaction at the workplace is important because it is directly linked to their performance and that of the organisation. Focusing on the factors which influence workplace satisfaction can aid an enterprise to secure its competitive advantage, knowing that it is only satisfied employees who are dedicated to their organisations and intend to stay with them for a long time. Such employees will provide customers with quality services, which leads to customer satisfaction, which has a positive impact on customer loyalty, thus causing sales to increase.

\subsection{Statistical relationships between the effectiveness of quality management practices and organisational performance}

In order to characterise the statistical relationships between the effectiveness of total quality management practices, represented by the independent variable Eff.QM and the dependent variables Org.eff, Emp.satisf, and Cust.satisf, which measure the organisational performance of SMEs, we conducted an analysis of association (correlation) relationships and a regression analysis using the STATA 16 software.

In order to analyse statistical association relationships, namely the correlations between the Eff.QM variable and the dependent variables Org.eff, Emp.satisf, and Cust.satisf, we determined the correlation coefficients as a statistical measure of the significance of the linear relationship between them. Based on the results obtained by calculating the correlation coefficients for linear regression, we may conclude that there is a significant positive correlation, which is: 
- very strong between the Eff.QM variable and the dependent variables Org.eff (0.8859) and Emp.satisf (0.8406);

- strong between the Eff.QM variable and the dependent variable Cust.satisf (0.7593)

Furthermore, in order to measure the impact of the independent variable Eff.TQM and the dependent variables Org.eff, Emp.satisf, and Cust.satisf, we conducted a regression analysis, the results of which are summarised in table 7.3.

Table 5. The impact of the independent variable Eff.QM on the dependent variables Org.eff, Emp.satisf, and Cust.satisf.

\begin{tabular}{|c|c|c|c|c|c|c|}
\hline Dependent variables & $\mathbf{N}$ & Prob $>$ F & R-squared & Coef. & t & $\mathbf{P}>|\mathbf{t}|$ \\
\hline Org.eff & 49 & 0.0000 & 0.7896 & .8947547 & 13,72 & 0.000 \\
\hline Emp.satisf & 51 & 0.0000 & 0.7161 & .9226225 & 10.89 & 0.000 \\
\hline Cust.satisf & 51 & 0.0000 & 0.5833 & .6802042 & 8.61 & 0.000 \\
\hline
\end{tabular}

By using the data in table 5, we will analyse statistically the impact of the independent variable Eff.QM on the dependent variables Org.eff, Emp.satisf, and Cust.satisf. The variation of the Eff.QM variable accounts for $78.96 \%$ of the variation of the Org.eff variable, $71.61 \%$ of the variation of the Emp.satisf variable, and 58.33\% of the variation of the Cust.satisf variable. The Eff.QM variable, for $\mathrm{P}>|\mathrm{t}|=0.000$, has a significant and positive impact on the variables Org.eff, Emp.satisf, and Cust.satisf. Between the independent variable Eff.QM and the three dependent variables there is a linear connection (a linear econometric model), which means that, for an increase by one unit of the effectiveness of quality management practices (Eff.QM), organisational effectiveness (Org.eff) will go up by 0.8947 units, employee satisfaction (Emp.satisf) by 0.9226 units, and customer satisfaction (Cust.satisf) by 0.6802 units. This means that respondents' perception of the effectiveness of quality management practices is good, which is why we find that they should be properly promoted within SMEs by adequately raising awareness of the importance of quality in increasing customer satisfaction and of the leadership's commitment in its relationship with customers through the adequate sharing of the organisation's values with all employees.

The fact that the smallest impact of the Eff.QM is exerted on the dependent variable Cust.satisf is explained by the reduced effectiveness of the actual operationalisation of procedures regarding customer relations and by a database that is poor in relevant information, which leads to negative consequences with respect to ensuring the effective management of one's experience with customers.

The significant impact of the Eff.QM variable on the three variables which illustrate organisational performance is explained by the effective integration of total quality management into the company's general strategy, while taking into account the particularities of SMEs, namely a simplified structure and flexibility in relation to the market. A further reason is strong client orientation, as proven by the results of the present study.

In sum, based on the results of the analysis of correlations and on the regression analysis, we may conclude that the variable Eff.QM is a good predictor of performance improvement as expressed by the variables Org.eff, Emp.satisf, and Cust.satisf, as a measure of the internal performance of the SMEs which make the object of this study.

\section{CONCLUSIONS}

This empirical study on ensuring the effectiveness of the implementation and operationalisation of TQM practices, based on an adequate model of managerial analysis and relying on statistical models of data analysis and processing, set out to identify best practices and specific problems that SMEs in the field of industrial production face, with the aim of identifying the most appropriate 
ways to improve performance through quality. The analysis highlights the concern of SME management for improving organisational quality and performance by improving the effectiveness of the implementation and operationalisation of TQM principles and best practices, according to ISO 9001:2015 requirements.

The aims of the study were attained due, in part, to the resulting statistical information and data relevant for the chosen theme, which enabled statistical processing using the STATA software. The study included the analysis of statistical association relationships, namely the correlations between the variables of the analysis model and the regression analysis for the determination of the impact between the variables under analysis, based on adequate econometric models.

As for the verification and analysis of the hypotheses formulated in the study, we can draw the following conclusions:

The effectiveness of total quality management, represented by the variable Eff.QM, has a significant impact on organisational performance, which is represented by the indicators below:

- Org.eff.According to the results of the regression analysis (table 3), the variation of the independent variable Eff.QM accounts for $78.96 \%$ of the variation of the Org.eff variable. The regression coefficient of the Eff.QM variable is 0.894, which highlights its significant and positive impact on the Org.eff variable. Thus, we conclude that the effectiveness of total quality management constitutes a good predictor of the improvement of organisational effectiveness as a measure of performance. Hypothesis $H 1.1$ holds;

- Emp.satisf. According to the results of the regression analysis (table 4), the independent variable Eff.QM accounts for $71.61 \%$ of the variation of the Emp.satisf variable. The regression coefficient of the Eff.QM variable is 0.922 , which highlights its significant and positive impact on the Emp.satisf variable. Thus, we conclude that the effectiveness of total quality management constitutes a good predictor of the improvement of employee satisfaction as a measure of performance. Hypothesis H1.2 holds;

- Cust.satisf. According to the results of the regression analysis (table 5), the independent variable Eff.QM accounts for $58.33 \%$ of the variation of the Cust.satisf variable. The regression coefficient of the Eff.QM variable is 0.680 , which highlights its significant and positive impact on the Cust.satisf variable. Thus, we conclude that the effectiveness of total

- quality management constitutes a good predictor of the improvement of customer satisfaction as a measure of performance. Hypothesis H1.3 holds.

Based on results of the study and the verification of the formulated hypotheses, we can state that the Effectiveness of TQM (Eff.QM) has a significant impact on the performance of the SMEs under analysis, which was measured using the non-financial indicators Cust.satisf, Emp.satisf, and Org.eff. This means that hypothesis H1 holds, i.e. the effectiveness of TQM represents a good predictor of the improvement of organisational performance in the SMEs being studied, which is illustrated by the indicators above.

The main recommendations for improving the effectiveness of total quality management practices as an important factor in improving the organisational performance of the SMEs under analysis can be summarised as follows:

- promoting a clear and adequate commitment of the company leadership, which should effectively support the implementation of TQM principles and the operationalisation of TQM practices in order to increase customer satisfaction;

- managers' balanced focus on both the operational and the strategic side of TQM;

- consolidating a strongly customer-oriented culture in order to capitalise on the potential benefits of effective TQM practices;

- creating an organisational climate that stimulates the efficient use of each employee's potential for an effective involvement in quality improvement processes; 
- acknowledging and motivating employees who achieve high-performance results in the field of quality improvement;

- assimilating knowledge management by encouraging collaborations with universities and consulting firms with a reputation in the field;

- setting realistic, ambitious and challenging quality objectives at all organisational levels;

- a periodical assessment of customer satisfaction;

- a periodical assessment of employee satisfaction;

- effective manager training in order to create the prerequisites for the implementation of a welldocumented and functional quality management system according to ISO 9001:2015 requirements.

\section{REFERENCES}

Bell, M. \& Omachonu, V. (2011). Quality system implementation process for business success. International Journal of Quality \& Reliability Management, 28 (7), 723-34.

Brah, S. A., Tee, S .S. L.\& Rao, B. M. (2002). Relationship between TQM and performance of Singapore companies. International Journal of Quality and Reliability Management, 9(4), 356379.

Brown, M. G. (2008). Baldrige Award Winning Quality. How to Interpret the Baldrige Criteria for Performance Excellence, 17th ed. New York: Taylor \& Francis Group.

Camp, S. D. (1994). Assessing the effects of organizational commitment and job satisfaction on turnover: An event history analysis approach. Prison Journal, 74, 279-306.

Chiarini, A. (2017). Risk-based thinking in accordance with ISO 9001: 2015 and risk sources European production SMEs intend to manage. TQM Journal, 29(2), 310-323.

Ellington, E. P., Jones, R. T. \& Deane, R., (1996). TQM Adoption Practices in the Family-Owned Business. Family Business Review, 9(1), 5-14. doi: 10.1111/j.1741 6248.

Demirbag, M., Tatoglu, E., Tekinkus, M. \& Zaim, S. (2006). An analysis of the relationship between TQM implementation and organizational performance: Evidence from Turkish SMEs. Journal of Manufacturing Technology Management, 17(6), 829-847.

Evangelos, P. \& Jiju, A. (2015). The quality efficiency of the ISO 9001 management system and its critical influence factors in production companies in Greece. International Journal of Production Research, 53(7), 2089-2099.

Fonseca, L. (2015a). From Quality gurus and TQM to ISO 9001:2015: a review of several quality paths. International Journal for Quality Research, 9(1), 167-180.

Fotopoulos, C. \& Psomas, E. (2010). The structural relationships between TQM factors and Organizational performance. The TQM Journal, 22(5), 539-52.

Garengo, P. (2009). A performance measurement system for SMEs taking part in quality award programmes. Total Quality Management, 20(1), 91-105.

Grant, D., Mergen, E. \& Widrick, S. (2002). Quality management in US higher education. Total Quality Management, 13 (2), 207-215.

Heras, I., Dick, G. P. M. \& Casadesús, M. (2002). ISO 9000 registration's impact on sales and profitability. A longitudinal analysis of performance before and after accreditation. International Journal of Quality \& Reliability Management, 19(6), 774-791.

Ilieş, L. (2003a). Managementul calităţii totale. Cluj-Napoca: Editura Dacia.

Ilieş, L.\& Crișan, E. (2011). Managementul calităţii totale. Cluj-Napoca: Editura Risoprint.

International Organization for Standardization. (2015). ISO 9001:2015 - Quality management systems - Requirements. International Organization for Standardization, (2015). ISO 9000:2015 - Quality management systems - Fundamentals and vocabulary. International Organization for Standardization. Geneva.. 
ISO 9000:2015. (2015). Quality management principles. Geneva.

Juran, J. M. (1999). Juran's quality handbook. 5th ed. New York: McGraw-Hill.

Kelada, J. (1990). La gestion integrale de la qualite. Pour une qualite totale. Quebec: Ed.Quafec.

Mathieu, J. E. \& Zajac, D. M. (1990). A review and meta-analysis of the antecedents, correlates, and consequences of organizational commitment. Psychological Bulletin, 108, 117-194.

Olaru, M. (2004). Managementul Calităţii. Ed. Economică, Bucureşti.

Olaru M., Stoleriu G., Langă, C. \& Flood I. (2011). Impactul implementării sistemului de management al calităţii ISO 9000 asupra procesului evaluării satisfacţiei clienţilor în cazul IMM-urilor din România. Revista Amfiteatru Economic, 13 (5), 669-678.

Powell, T. C. (1995). Total quality management as competitive advantage: a review and empirical study. Strategic Management Journal, 16(1), 15-37.

Psomas, E., Kafetzoupoulos, D. P. \& Fotopoulos, C. (2013). Developing and Validating a Measurement Instrument of ISO 9001 Effectiveness in Food Manufacturing SMEs. Journal of Manufacturing Technology Management. 24 (1), 52-77. 